\title{
Introduction and Summary of the 2018 Dietary Glutamate Workshop
}

\author{
Luc Cynober $^{\mathrm{a}}$ John D. Fernstrom ${ }^{\mathrm{b}}$ Berthold Koletzko ${ }^{\mathrm{c}}$ \\ Ivonne M.C.M. Rietjens ${ }^{d}$ Ashley Roberts ${ }^{e}$ David R. Tennant ${ }^{f}$ \\ Daniel Tomég Charles V. Vorhees ${ }^{\text {h }}$
}

a Hôpital Cochin, Service de Biochimie, and Faculté de Pharmacie, Université Paris Descartes, Paris, France;

${ }^{b}$ Department of Psychiatry and Department of Pharmacology and Chemical Biology, University of Pittsburgh School of Medicine, Pittsburgh, PA, USA; ' Ludwig-Maximilians-Universität Munich, Dr. von Hauner Children's Hospital, University of Munich Medical Center, Campus Innenstadt, Munich, Germany; ${ }^{\mathrm{d}}$ Division of Toxicology, Wageningen University and Research, Wageningen, The Netherlands; ${ }^{\mathrm{e}}$ Intertek Scientific and Regulatory Consultancy, Health, Environmental and Regulatory Services (HERS), Mississauga, ON, Canada; ${ }^{\mathrm{f} F o o d}$ Chemical Risk Analysis, East Sussex, UK; 9 UMR PNCA, INRA, AgroParisTech, Université Paris-Saclay, Paris, France; ${ }^{\text {h}}$ Department of Pediatrics, University of Cincinnati College of Medicine and Division of Neurology, Cincinnati Children's Research Foundation, Cincinnati, OH, USA

\section{Keywords}

Glutamate · Amino acid · Risk assessment · European food safety authority · Toxicology

\begin{abstract}
The 2018 Dietary Glutamate Workshop was organized and sponsored by the International Glutamate Technical Committee to provide a platform for a broad expert discussion on all relevant aspects of glutamate metabolism and safety in human nutrition. The participants reached a consensus with previous safety evaluations conducted by the global expert bodies, but contradicted the 2017 re-evaluation of dietary glutamates by the European Food Safety Authority, which proposed a group acceptable daily intake (ADI) of $30 \mathrm{mg} / \mathrm{kg}$ body weight per day. The participants of the Workshop con-
\end{abstract}

\section{KARGER}

E-Mail karger@karger.com www.karger.com/anm

\section{(C) 2018 The Author(s) \\ Published by S. Karger AG, Basel} Ton NonCommercial-NoDerivatives 4.0 International License (CC BY-NC-ND) (http://www.karger.com/Services/OpenAccessLicense). Usage and distribution for commercial purposes as well as any distribution of modified material requires written permission. cluded that the present knowledge on metabolism, kinetics, developmental and general toxicity of dietary glutamates did not warrant a change in the previous ADI of "not specified."

@ 2018 The Author(s)
Published by S. Karger AG, Basel

The 2018 Dietary Glutamate Workshop consisted of a set of presentations and discussion sessions among 8 leading experts on various aspects of amino acid (food ingredients) metabolism, toxicology, and exposure assessment. The Workshop participants recognized the unambiguous presence of free (non-protein bound) glutamate in food and those glutamate forms that are "added to food" in various flavor-enhancing formulations, such as yeast extracts, hydrolyzed vegetable proteins, bouillons or Parmesan 
cheeses. Whatever the form of free glutamate in food (dietary glutamate), the human body has no means to recognize its origin, and thus processes all glutamate forms equally. Consequently, any safety evaluation of dietary glutamate should include all available forms, as already standardized by the European Food Safety Authority (EFSA) in the case of lycopene [1], vitamins, chlorophylls, beetroot red; and virtually all naturally present food constituents also used as food additives for specific technological applications. Other consensus points reached during the Workshop are described in detail in seven individual articles that make up the main body of this Proceedings, and are further summarized here-below $(\mathrm{A}-\mathrm{H})$ :

A. Glutamate is a non-essential amino acid that is central to nitrogen and energy metabolisms of the human body. Glutamate metabolism is mostly compartmentalized within the cells, its inter-organ exchanges being limited to a flux from liver to muscle. Glutamate originating from food (dietary glutamate) is absorbed from the intestinal lumen and is metabolized by enterocytes, mainly for the production of energy to support intestinal motility and other functions. Glutamate is the most important fuel for intestinal tissue, it is involved in gut protein metabolism and is the precursor of different important molecules produced within the intestinal mucosa $[2,3]$.

B. Glutamate catabolism is extremely intense in the splanchnic area and for the usual amounts of intake of monosodium glutamate (MSG) used as a food additive (up to 1-2 g), about $95 \%$ of orally ingested glutamate is metabolized in first-pass by splanchnic tissues and the remaining fraction, which is absorbed from the gut into the systemic circulation, is diluted in the systemic glutamate turnover and does not significantly affect the blood glutamate concentration, or only to a very limited extent, when provided together with a meal [2-4]. Pharmacological doses of glutamate ( $>5-10 \mathrm{~g})$, which are above the doses consumed, particularly when ingested in a water solution on an empty stomach, may increase the plasma circulation of glutamate; however, the appearance of glutamate in the circulation is blunted for a significant part if free glutamate, irrespective of its dietary origin, is coingested with a food which is the usual form of intake (e.g., [5]).

C. As the principal signal molecule of the basic umami taste, glutamate is involved in the natural oral and postoral nutrient chemo-sensing that is mediated via the umami receptors located on the tongue and also throughout the gut. The taste and oral sensation of glutamate triggers the cephalic phase response of digestion to prepare for food digestion. Umami receptors found in the taste cells on the tongue respond to glutamate with no distinction between free glutamate which is naturally occurring in food and that which is added to foods. Dietary glutamate is sensed again in the gut, and the subsequent physiological responses are mediated through gustatory nerves and both humoral and neural (vagal) gut-brain pathways, with an impact on digestive processes and feeding behavior [3].

D. The first dietary exposure to glutamate in infants is through human milk. Glutamate is the quantitatively dominant free (non-protein bound) amino acid in human milk. Based on global cross-sectional data, a typical breastfed infant obtains a mean free glutamate intake of $35.7 \mathrm{mg} / \mathrm{kg}$ body weight per day (upper end of the normal range is $134.6 \mathrm{mg} / \mathrm{kg}$ body weight per day). Based on recent precisely collected longitudinal data in milk of European women, the estimated mean daily intakes are $40 \mathrm{mg}$ (upper range intakes $70.2 \mathrm{mg} / \mathrm{kg}$ ); with median concentrations in cows' milk formula, daily intakes are $0.7 \mathrm{mg} / \mathrm{kg}$ body weight and with extensive protein hydrolysate formula $171.7 \mathrm{mg} / \mathrm{kg}$ body weight, with no indication of adverse effects $[6,7]$. Like adults, infants utilize dietary glutamate almost entirely in the splanchnic organs, with no appreciable effect of marked variation in dietary intakes on plasma glutamate concentrations. Estimated free glutamate intakes in breastfed infants are up to 4.5 -fold higher than the ADI set by the EFSA for the total population including infants, and the respective intakes of infants fed a formula based on an extensive protein hydrolysate are up to 8.3fold higher. There is no reason to assume that feeding human milk or extensive protein hydrolysate infant formulae would be unsuitable or unsafe for infants. Consequently, setting an ADI below the range of the normal intakes with a long history of use, namely below $250 \mathrm{mg} / \mathrm{kg}$ and day, seems inappropriate [6].

E. The dietary exposure to glutamate in adults is extensive, due to its ubiquitous presence in foods. Levels of dietary glutamate after acid hydrolysis can be as high as $50 \mathrm{~g} / \mathrm{kg}$ of food in certain oilseeds. Levels of glutamate from protein in animal products are generally around $25 \mathrm{~g} / \mathrm{kg}$ of food. Moreover, free glutamates can occur in relatively high concentrations ( $18 \mathrm{~g} / \mathrm{kg}$ of food) in certain fermented foods such as cheese, preserved meats, and soy sauce, depending on aging and maturation. Food additive use levels for glutamates (E620-E625) in the European Union are limited to $10 \mathrm{~g} / \mathrm{kg}$ of food in 65 broad categories of foodstuffs by the provisions of Regulation (EC) No. 1333/2008 and Commission Regulation (EU) No. 1129/2011. However, from a practical viewpoint, glutamates would only be used in savory foods to modu- 
late the umami taste and so would be used in only a small proportion of the foods for which they are authorized. Conservative assessments of potential high level intakes of glutamates from the use of E620-E625 range up to $80 \mathrm{mg} / \mathrm{kg}$ body weight per day for toddlers and schoolage children. Estimated high level intakes of free glutamate from natural sources give a very similar result. Intakes of glutamate from amino acids in proteins can range up to 500 or $1,000 \mathrm{mg} / \mathrm{kg}$ body weight per day for the same age groups. The use of glutamates as food additives results in free glutamate intakes comparable to those from natural sources and contributes only a small proportion to total intakes of glutamate from all sources [8].

F. The original safety concerns with dietary glutamate, especially with the food additive forms, appeared in the late 1960s, due to the hypothesis that passage of glutamate into the systemic circulation ultimately increases brain glutamate levels, causing functional disruptions. By the 1980 s, it became apparent that experiments in rodents injected with high doses of MSG were not useful in evaluating the safety of dietary glutamate in the human food supply with regard to brain function. First, the extent to which plasma glutamate concentrations must rise to produce effects in the rodent brain are never encountered in humans consuming glutamate in the context of normal diets where glutamate is highly metabolized in the splanchnic area. Second, studies in animals daily ingesting enormous amounts of MSG in their diets (up to $25 \mathrm{~g} / \mathrm{kg}$ body weight per day in lactating females) over multiple generations do not cause any of the adverse effects reported to occur following injected doses of MSG. Third, it is important to note that food-added glutamate intake in the human diet is self-limiting, based on the fact that the perceived pleasantness of ingested glutamate diminishes markedly as its concentration rises, in contrast to the perceived pleasantness of sugar (sweet taste). Together, the findings from non-human primate and human studies provide evidence that MSG in the food supply presents no neurotoxicity or neurodevelopmental risks $[9,10]$.

G. The above arguments relate closely to behavioral aspects of developmental neurotoxicity, which is highly relevant because a preliminary behavioral neuro-developmental study conducted in 1979 [11] was used by EFSA (2017) to establish a no-observed-adverse-effect-level (NOAEL) [12]. The author of the original 1979 study reevaluated the relevance of his own results in the framework of the Workshop [13]. He noted that Sprague-Dawley rats were fed diets containing various MSG doses prior to conception, throughout gestation and lactation, and to the offspring until 90 days of age [11]. There were 21 func- tional tests with 31 dependent variables and 10 body weight and histological outcomes. Of the functional tests, 4 were significant with respect to the tested substance (MSG). Two effects were on swimming development: one was an improvement and the other an atypical minor delay of no significance. Two effects were on active avoidance, neither providing evidence of consistency. One effect was on passive avoidance, but was an improvement not a deficit. The last effect was on open-field rearing in the absence of its normal association with locomotion changes.

$\mathrm{H}$. The principal author of the study concluded, as he did in 1979 and as did the U.S. Food and Drug Administration who sponsored the study, that there was no evidence in these data that dietary MSG was developmentally neurotoxic, hence, there was no basis for changing the NOAEL for dietary MSG [13]. Indeed, the behavioral neuro-developmental test battery has been consolidated into the international guidelines, namely OECD TG246, Redbook IV.C9.a and ICH S5, with "swimming development," "open field activity and emotionality," and "active avoidance" not listed.

The recent re-evaluation of the use of glutamic acids and glutamates by the EFSA proposed a group ADI of $30 \mathrm{mg} / \mathrm{kg}$ body weight per day based on a NOAEL derived from rodent developmental neuro-behavior [12]. The above commentaries $(A-G)$ indicate that such an ADI is at a level below the normal dietary intake and that even mean intakes of free glutamate by breastfed infants are considerably higher than this ADI. The developmental toxicity study selected by the EFSA on which to base the $\mathrm{ADI}$ has not been used by other regulatory authorities worldwide as the basis of their conclusions on the safety assessment of glutamates, although it has been available for nearly 40 years. In addition, toxicokinetic data provide support for eliminating the use of the uncertainty factor for interspecies differences in kinetics. Our toxicological analysis [14] came to a conclusion that a 3-generation reproductive toxicity study in mice, that included extensive brain histopathology, provided better evidence and showed no effects up to the highest dose tested of 6.0 $\mathrm{g} / \mathrm{kg}$ body weight per day. Furthermore, available kinetic data support the use of a compound-specific uncertainty factor of 25 instead of 100, indicating an ADI of at least $240 \mathrm{mg} / \mathrm{kg}$ body weight per day.

The current estimated dietary exposure to glutamates resulting from use as food additives (E620-E625) at both the mean and the 95th percentile remains far below this suggested value of at least $240 \mathrm{mg} / \mathrm{kg}$ body weight per day [14]. Considering the metabolic pathways of glutamate, the self-limiting character of glutamate taste (umami) 
[15], and the fact that a practical limit on glutamate use in final foods already exists $(10 \mathrm{~g} / \mathrm{kg}$ of food), there are no compelling arguments to warrant change of the ADI of "not specified." This fact has been already recognized by the other respected regulatory bodies, including the US Food and Drug Administration and the Food Standards Australia New Zealand [16].

\section{Disclosure Statements}

The Workshop preparation, setting, and attendance have been supported by the International Glutamate Technical Committee (IGTC), Brussels. The views of the authors are their own, and do not necessarily reflect those of the IGTC. The authors thank Dr. Miro Smriga (IGTC) for assistance with the manuscript preparation and Workshop organization.

\section{References}

1 EFSA Assesses Safety of Lycopene in Foods. https://www.efsa.europa.eu/en/press/ news/08041 (cited September 12, 2018).

2 Cynober L: Metabolism of dietary glutamate in adults. Ann Nutr Metab 2018; 73(suppl 5):5-14.

3 Tomé $\mathrm{D}$ : The roles of dietary glutamate in the intestine. Ann Nutr Metab 2018;73(suppl 5): 15-20.

4 Reeds PJ, Burrin DG, Jahoor F, Wykes L, Henry J, Frazer EM: Enteral glutamate is almost completely metabolized in first pass by the gastrointestinal tract of infant pigs. Am J Physiol 1996;270:E413-E418.

5 Stegink LD, Filer LJ Jr, Baker GL, Bell EF: Plasma glutamate concentrations in 1-yearold infants and adults ingesting monosodium L-glutamate in consommé. Pediatr Res1986; 20:53-538.

6 Koletzko B: Glutamate supply and metabolism in infants. Ann Nutr Metab 2018;73(suppl 5):29-35.
7 van Sadelhoff JHJ, van de Heijning BJM, Stahl B, Amodio S, Rings EHHM, Mearin ML, Garssen J, Hartog A: Longitudinal variation of amino acid levels in human milk and their associations with infant gender. Nutrients 2018;10:pii:E1233.

8 Tennant DR: Review of glutamate intake from both food additive and non-additive sources in the European Union. Ann Nutr Metab 2018;73(suppl 5):21-28.

9 Fernstrom JD: Monosodium glutamate in the diet does not raise brain glutamate concentrations or disrupt brain functions. Ann Nutr Metab 2018;73(suppl 5):43-52.

10 Stegink LD, Pitkin RM, Reynolds WA, Filer L Jr, Boaz DP, Brummel MC: Placental transfer of glutamate and its metabolites in the primate. Am J Obstet Gynecol 1975;122:70-78.

11 Vorhees CV, Butcher RE, Brunner RL, Sobotka TJ: A developmental test battery for neurobehavioral toxicity in rats: a preliminary analysis using monosodium glutamate calcium carrageenan, and hydroxyurea. Toxicol Appl Pharmacol 1979;50:267-282.
12 EFSA Reviews Safety of Glutamates Added to Food. https://www.efsa.europa.eu/en/press/ news/170712 (cited September 12, 2018).

13 Vorhees CV: A test of dietary monosodium glutamate developmental neurotoxicity in rats: a reappraisal. Ann Nutr Metab 2018; 73(suppl 5):36-42.

14 Roberts A, Lynch B, Rietjens IMCM: Risk assessment paradigm for glutamates. Ann Nutr Metab 2018;73(suppl 5):53-64.

15 Yamaguchi S, Takahashi C: Hedonic functions of monosodium glutamate and four basic taste substances used at various concentration levels in single and complex systems. Agri Biol Chem 1984;48:1077-1081.

16 MSG in Food. http://www.foodstandards. gov.au/consumer/additives/msg/Pages/default.aspx (cited September 12, 2018). 